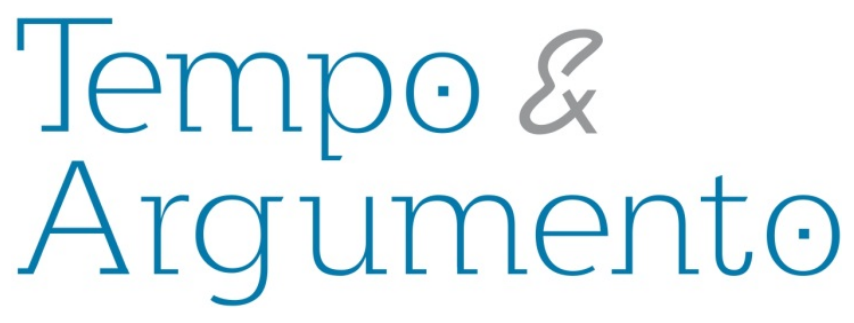

\title{
La representación de la infancia en América Latina y el Comité de los Derechos del Niño (1990-2013)
}

\begin{abstract}
Resumen
La construcción social de la infancia está sometida a discursos científicos, populares, académicos, etc. que han configurado una amalgama de imágenes y representaciones alrededor de los niños, las niñas y los adolescentes. Entre estos discursos, queremos destacar el elaborado por el Comité de los Derechos del Niño, órgano de seguimiento de la Convención sobre los Derechos del Niño (CDN), de 1989, que, desde la década de los 90, no ha cesado de emitir observaciones y recomendaciones en las que queda patente un discurso hegemónico, compartido con el Fondo de las Naciones Unidas para la Infancia (Unicef), sobre la infancia. El análisis que hemos abordado parte de una fuente muy rica en matices como son los informes que dicho Comité emite a la hora de evaluar públicamente la situación de la infancia en los países del mundo. En concreto, nos centramos en un corpus documental importante con referencia a América Latina, pues analizamos todos los informes comprendidos entre 1990 y 2013 y que recogen información suficiente sobre la situación de la infancia. Entre esas fechas, todos los países de la región enviaron sucesivos informes sobre la implementación de los derechos de las niñas, los niños y los adolescentes al mencionado Comité. El resultado de la investigación nos ofrece un perfil de la infancia en América Latina caracterizado por unos trazos relativos a la defensa de una infancia libre de violencia, digna y adecuada y una infancia sin discriminación en los 25 años de vigencia de la Convención.
\end{abstract}

Palabras clave: Convención sobre los Derechos del Niño; América Latina; Representación de la Infancia; Comité de los Derechos del Niño.

\author{
Paulí Dávila* \\ Catedrático de Historia de la Educación de la \\ Universidad del País Vasco/Euskal Herriko \\ Unibertsitatea. \\ Espanha \\ pauli.davila@ehu.eus
}

\section{Luis M. Naya*}

Profesor titular de Educación Comparada de la Universidad del País Vasco/Euskal Herriko Unibertsitatea Espanha luisma.naya@ehu.eus

\section{Para citar este artículo:}

DAVILA, Paulí; NAYA, Luis M. La representación de la infancia en América Latina y el Comité de los Derechos del Niño (1990-2013). Tempo e Argumento, Florianópolis, v. 7, n. 14, p. 48 - 84, jan./abr. 2015.

\section{DOI: $10.5965 / 2175180307142015048$}

http://dx.doi.org/10.5965/2175180307142015048

\footnotetext{
* Los autores son miembros del Grupo de Estudios Históricos y Comparados en Educación - Garaian, reconocido por el Gobierno Vasco con el número IT 603-13 y de la Unidad de Formación e Investigación "Educación, Cultura y Sociedad (UFI 11/54)" de la Universidad del País Vasco/Euskal Herriko Unibertsitatea UPV/EHU.
} 
The representation of children in Latin America and the Committee on the Rights of the Child (1990-2013)

\begin{abstract}
The social construction of childhood is subjected to scientific, popular, academic and other discourses, which have shaped an set of images and representations around children and adolescents. Among these discourses, we want to highlight that which is prepared by the Committee on the Rights of the Child, which followed the Convention on the Rights of the Child (1989). This Committee, since the 90s, has continued to make observations and recommendations in which is clear a hegemonic discourse, shared with the United Nations Children's Fund (Unicef), on childhood. The analysis we have done part of a very rich source of nuances such as the reports that the Committee issues when assessing publicly the situation of childhood in countries around the world. Specifically, we focus on a major documentary corpus with reference to Latin America, for we have analyzed all reports between 1990 and 2013 and that contain enough information on the situation of childhood. Between those dates, all countries in the region have sent successive reports on the implementation of the rights children and adolescents to that Committee. The result of research gives us a profile of childhood in Latin America characterized by a few features related to the defense of a childhood free from violence, dignified and appropriate and a childhood without discrimination in the 25 years in which Convention is in force.
\end{abstract}

Keywords: Convention on the Rights of the Child; Latin America; Representation of childhood; Committee on the Rights of the Children.

\section{A representação da infância na América Latina e o Comitê dos Direitos da Criança (1990-2013)}

\section{Resumo}

A construção social da infância está sujeita a discursos científicos, populares, acadêmicos etc., que configuraram um conjunto de imagens e representações em torno das crianças e dos adolescentes. Entre estes discursos, queremos destacar o elaborado pelo Comitê dos Direitos da Criança, órgão resultante da Convenção sobre os Direitos da Criança, de 1989, que, desde a década de 1990, não cessou de emitir observações e recomendações em que fica claro um discurso hegemônico, compartilhado com o Fundo das Nações Unidas para a Infância (Unicef), sobre a infância. A análise que abordamos parte de uma fonte muito rica em matizes, como são os informes que o referido Comitê emite na hora de avaliar publicamente a situação da infância nos países do mundo. Concretamente, concentrar-nos-emos em um corpus documental importante com referência à América Latina, pois analisamos todos os informes compreendidos entre 1990 e 2013 e que contêm informações suficientes sobre a situação da infância. Entre essas datas, todos os países da região enviaram sucessivos informes sobre a implementação dos direitos das crianças e dos adolescentes ao mencionado Comitê. O resultado da investigação nos oferece um perfil da infância na América Latina caracterizado por traços realtivos à defesa de uma infância livre de violência, digna e adequada e uma infância sem discriminação nos 25 anos de vigência da Convenção.

Palavras-chave: Convenção sobre os Direitos da Criança; América Latina; Representação da infância; Comitê dos Direitos da Criança. 


\section{Introducción}

En las tres últimas décadas escribir sobre la infancia, desde la perspectiva de los derechos, es una tarea habitual tanto en el mundo académico como en la prensa cotidiana o en los medios electrónicos. Esta presencia mediática también tiene que ver mucho con el contexto en el que se ha producido, marcado por unas décadas donde la situación de vulnerabilidad de la infancia se ha hecho más visible. Los casos de todo tipo de violencia contra los niños y niñas han ocupado las primeras páginas de la prensa y existe una mayor conciencia sobre los derechos de los niños, niñas y adolescentes, sobre todo a partir de la aprobación en 1989 de la Convención sobre los Derechos del Niño $(C D N)$. Se trata de una evidencia que reafirma la presencia cada vez mayor de la infancia en el pensamiento político, en las prácticas sociales o en las políticas de ayuda y protección. La infancia también ha cobrado un protagonismo en los programas de políticas públicas, tanto en los países en desarrollo como en los países minoritarios (nos referimos a los pocos que en el mundo gozan de un alto nivel de bienestar social). Es la soberanía de la infancia que estaba reclamando, a su manera, su parte del pastel de la Historia. La fuerza de su presencia ha abierto un nuevo campo de estudio, denominado Children Studies, que comparte el panorama de investigación junto con los estudios de género y otras disciplinas emergentes, caracterizadas, sobre todo, por su interdisciplinariedad y el uso de nuevas metodologías cualitativas.

Esta irrupción de la infancia en la agenda política y en el quehacer de muchos investigadores e investigadoras ha producido un discurso hegemónico donde la infancia se nos ha presentado como universal -entendiendo por universal el modelo único de la infancia de los países minoritarios-, al margen de la variopinta realidad en la que viven, y han vivido, tantos niños y niñas en el mundo. Se trata de un discurso poco emancipatorio para los propios niños y niñas, en tanto que, en la mayoría de los casos, los niños permanecen silenciados y continuamos siendo los adultos quienes les usurpamos la palabra, incluso cuando recurrimos a sus voces, como una estrategia con fines retóricos. Esta situación ha posibilitado la construcción de una representación de la infancia donde se muestra una imagen de los niños y niñas con pocos matices, a pesar de que las evidencias demuestren lo contrario. 
Desde la perspectiva historiográfica resulta de utilidad el nuevo paradigma sobre la infancia, basado en el enfoque de derechos humanos que puede cambiar la mirada, las voces y los objetos; buscando nuevas fuentes (por ejemplo, la memoria de las experiencias infantiles, sus propios relatos, sus dibujos, su participación en tantas actividades de la vida cotidiana), donde poder explicar de otra forma la presencia de los niños y niñas en la historia. El marco que proporciona el enfoque de derechos de la infancia permite abordar un amplio campo donde se pueden diversificar ámbitos y categorías, líneas y ejes de dependencia, considerando a los niños y niñas como sujetos históricos. Este enfoque de los derechos de los niños continúa siendo útil para comprender la nueva situación de la infancia en el mundo, pero también se transforma en una herramienta para explicar los procesos históricos de la infancia tanto en situaciones traumáticas como en momentos cotidianos de los niños y niñas en la escuela, sin exclusiones, con derechos.

Se trata de asumir, con críticas, el discurso hegemónico para comprender su construcción y el uso actual e histórico que puede hacerse. Un ejemplo de este discurso lo podemos encontrar en organismos como Fondo de las Naciones Unidas para la Infancia (Unicef) o el Comité de los Derechos del Niño que están produciendo una representación institucional alrededor de la infancia que, en algunos casos, tiene anclajes muy sólidos en el discurso tradicional sobre la infancia. La hegemonía de la representación construida por estos organismos, contribuye a la circulación de un discurso del que participan entidades sociales, organismos institucionales, ONG, medios de comunicación, familias, y también comunidades discursivas y grupos científicos, que presentan una determinada concepción universal de la infancia y en la que difícilmente caben todas las infancias posibles y reales.

El objetivo de este artículo es analizar el discurso construido por el Comité de los Derechos del Niño, órgano de seguimiento de la CDN, de 1989, que, desde su creación, en la década de los 90, ha emitido observaciones y recomendaciones en las que queda patente un discurso sobre la infancia que se está convirtiendo en hegemónico. Para ello, hemos realizado un análisis a partir de una fuente muy rica en matices, como son las Observaciones que dicho Comité emite a la hora de evaluar públicamente la situación de la 
infancia en los diversos países del mundo. En concreto nos centramos en un corpus documental importante con referencia a América Latina, pues recogemos todos los informes comprendidos entre 1990 y 2013, y que aportan información relevante sobre la situación de la infancia durante este periodo, ofreciendo una determinada representación de la infancia.

\section{Las políticas de protección y la representación de la infancia contemporánea}

En la historiografía reciente sobre la infancia existen diferentes formas de acercarse a su conocimiento, tanto de una perspectiva mundial (BARDET, 2003; BECCHI, 2010; BECCHI y JULIA, 1996; FASS, 2004), como latinoamericana (SOSENSKI, 2012; PADILLA y OTROS, 2008; LOPES y OTROS, 2007, DÁVILA, 2010; RODRÍGUEZ y MANARELI, 2007) o española (DÁVILA y NAYA, 2005). Una de estas formas es el estudio de la protección infantil, pudiendo afirmarse que, durante los siglos XIX y XX, cada país occidental siguió sus propias dinámicas para desarrollar políticas de protección y ayuda a la infancia. No obstante, se aprecia que, a pesar de las tradiciones culturales, religiosas, económicas, sociales y educativas, existe un cierto consenso en aplicar el mismo tipo de políticas de ayuda a los niños y a sus madres, debido a las consecuencias de la industrialización y a las altas tasas de mortalidad infantil.

En este sentido, uno de los elementos más novedosos, a principios del siglo XX, fue la transición de las políticas protectoras nacionales a los acuerdos supranacionales. De esta manera, en Europa y América compartieron las mismas inquietudes sobre protección a la infancia. Al desarrollo de este fenómeno contribuyó la celebración de congresos, que lograron armonizar un discurso médico y social compartido institucionalmente, con la expansión de la puericultura como disciplina formativa de la infancia "normal", el nuevo papel de una maternidad responsable o la atención a una infancia en peligro o peligrosa. Todo ello será el germen de Tratados Internacionales (DÁVILA y NAYA, 2006) y del surgimiento de organismos internacionales, a raíz de las dos guerras mundiales (la Sociedad de Naciones y las Naciones Unidas). 
En este proceso de transición, y también de interacción, se fragua, como indica Rollet (2001), una "cultura común" a partir de los congresos internacionales. Muchos países participaron en los debates sobre la definición del niño, las formas de protegerlo, el trabajo infantil o el papel de la educación. Las sociedades médicas, educativas o de higiene también se preocuparon por un problema clave desde el siglo XIX: la mortalidad infantil y las condiciones de pobreza en las que vivían muchas familias. De esta manera, la construcción del concepto moderno del menor está basada en el derecho y en las distintas formas de intervención del Estado que "jugaron un papel crucial en la constitución del concepto moderno de menor" (THERBORN, 1993, p. 87). Este conjunto de fenómenos contribuyeron a construir un discurso donde la infancia irá adquiriendo una representación social con un perfil determinado: los niños son seres necesitados de ayuda.

Las discusiones en los congresos sobre la infancia giraban alrededor de dos polos: “un polo más jurídico y teórico y otro más pragmático” (ROLLET, 2001, p. 99). En relación con el polo jurídico, se aprecia la preocupación por las responsabilidades de los Estados o de las familias con respecto a los niños abandonados, la delincuencia juvenil o la tutela. Ya en 1883 a raíz del primer Congreso Internacional de Protección a la Infancia, celebrado en París, se aprecia este interés. En cambio, al polo pragmático, médico-higienista, le preocupaba más la primera infancia y el cuidado de las enfermedades más comunes, además de la apertura al campo de la puericultura y la introducción de la leche esterilizada, como puede observarse en los diferentes congresos sobre higiene y salud. En este segundo ámbito, son de resaltar la celebración de los tres Congresos Internacionales de Gotas de Leche (París, 1905; Bruselas, 1907 y Berlín 1911) que tuvieron un éxito sin precedentes, tanto por el importante número de países que participaron, como por la presencia de pediatras de alto nivel científico. Por supuesto, estos congresos tuvieron sus consecuencias en los diferentes países con la creación de este tipo de instituciones y normativas legales.

Estos congresos abordaron temas muy variados: higiene, educación familiar, pediatría, tribunales para niños, colonias de vacaciones, asistencia pública, etc. (BARONA, 2004; DÁVILA y NAYA, 2006). En esta amalgama de intereses es donde se construye esa 

de manera muy destacada, Francia, seguida de Bélgica -con un 50 por 100 menos de congresos-, Italia, España, Estados Unidos, Suiza, Alemania, Inglaterra, Argentina, Hungría, Suecia, Brasil, y otros países latinoamericanos debido a la celebración de los Congresos Panamericanos del Niño, iniciados en 1916 (GUY, 1988; NUNES, 2008, 2011).

Por otra parte, las asociaciones internacionales también tendrán su parte importante en la organización de este tipo de congresos, que se irán celebrando con cierta periodicidad. Entre las más importantes, podemos destacar la Asociación Internacional para la Protección de la Infancia, la Unión Internacional para la Protección de la Infancia en la Primera Edad, La Unión Internacional de Socorros de Niños y la Liga de Sociedades de la Cruz Roja. Estas cuatro asociaciones lograron colaborar conjuntamente en la celebración del Congreso Internacional de Protección a la Infancia, celebrado en julio de 1928 en París, y al que asistieron más de 2000 delegados extranjeros.

La celebración de estos congresos, además, conllevaba la publicación de libros, folletos divulgativos y otro tipo de material, que permitía dar a los mismos mayor resonancia pública. A partir de las relaciones surgidas en los congresos se irá fraguando una red de relaciones y asociaciones internacionales, con sus respectivos comités nacionales y organismos interdependientes que favorecerán la circulación de un discurso compartido sobre una nueva representación de la infancia. Por primera vez, los niños van a ser un grupo de población específico de protección en diversos tratados internacionales, a partir de 1924.

Al margen de esta actividad internacional, a través de los congresos y reuniones científicas, queremos hacer mención a un texto curioso, no por su contenido, sino por su título: Les droits de l'enfant de Paul Godin (1911), cuya primera edición fue en 1881. Se trata de una tesis doctoral, cuyo eje principal es la medicina familiar y, sobre todo, la atención a las necesidades de los niños a fin de que crezcan sanos. Por lo tanto, el concepto de derecho que utiliza no tiene sentido legal sino de necesidad básica. Así, por ejemplo, habla del derecho del cuerpo, cuando en realidad se refiere a las necesidades corporales 
de los niños. No obstante, resulta innovador el planteamiento que hace el autor, en tanto que plasma también la necesidad de una educación en libertad y el respeto por ciertos derechos de la primera infancia. En su obra hay una crítica a las prácticas contaminantes del pasado y ofrece una guía de puericultura. Su autor es un reputado médico militar que publicó un importante volumen de obras sobre medicina y antropología médica. Esta obra puede insertarse en la producción que, sobre este campo, se realizó desde mediados del siglo XIX y primer tercio del siglo XX. Por lo tanto, este texto sigue un discurso ya detectado en la literatura médica y en la antropología médica. Asimismo, coincide con los temas tratados en los congresos a los que hemos hecho mención (BOLTANSKI, 1972).

Como colofón de todo este proceso, podemos observar la existencia, en el primer tercio del siglo $\mathrm{XX}$, de una red internacional fraguada alrededor de congresos, asociaciones y publicaciones, sobre todo en Europa y en las dos Américas dedicadas a la atención a la infancia. El objetivo de la misma era atender la protección a la infancia abandonada física y moralmente, por utilizar una expresión muy extendida en una época, donde los derechos de los niños y niñas eran desconocidos. Por lo tanto, en esta época se fue fraguando un discurso supranacional donde la representación de la infancia tiene el siguiente perfil: los niños deben ser protegidos de las situaciones vulnerables, atendiendo sus necesidades básicas, tanto físicas como morales. Nos ha interesado poner de manifiesto esta situación incipiente para comprender el surgimiento de los diferentes tratados sobre los derechos del niño, que estudiamos a continuación.

\section{La representación de la infancia en los tratados internacionales}

La representación de la infancia desde la perspectiva histórica supranacional, con enfoque de derechos humanos, ha sido escasamente estudiada (CAMPOY, 2006; DEPAEPE, 1998). No obstante, hay que resaltar la importancia que tiene la circulación del discurso sobre la infancia, ya que se trata de un conjunto de ideas compartidas no solo por los expertos y profesionales dedicados a la protección de la infancia, sino también por las familias y población en general. Esta cuestión ha sido abordada por Moody (2014, 2015), quien se refiere a la circulación de los derechos del niño a través de los tres 
tratados a los que a continuación nos referiremos. Su abordaje es desde una perspectiva socio-histórica y de los contextos en los que se produce cada uno de los Tratados. De esta manera, detecta los conceptos, las instituciones, los agentes y contextos que han influido en los derechos de la infancia. Por lo tanto, la aprobación de los tratados sobre los derechos de la infancia debe entenderse como una afirmación que ofrece un discurso institucional, trasnacional y universal, construido por agentes políticos, organismos no gubernamentales y otras instituciones sociales. Esta construcción ha posibilitado una imagen "universal" y consensuada de la infancia que, finalmente, se ha vuelto hegemónica. Se trata de un discurso que atraviesa las culturas, los espacios y las políticas nacionales, convirtiendo a la infancia en un objeto transnacional y abordado desde una perspectiva interdisciplinaria. Por lo tanto, la institucionalización de los derechos del niño a través de agencias supranacionales ha contribuido a la difusión, circulación e internacionalización de un discurso limitado de la infancia. En este sentido, es importante resaltar que el "invento" de los derechos del niño se produce en un contexto supranacional, donde los tratados internacionales han sido aprobados en Naciones Unidas.

Al analizar estos tres tratados las dos primeras cuestiones que nos planteamos son las relativas a la extensión de los propios textos y a la identidad los promotores de las mismas. Así, mientras la Declaración de Ginebra de $1924^{\dagger}$ contiene cinco principios y fue promovida por una organización no gubernamental y se debe al empeño personal de Eglatyne Jebb (1876-1928), la Declaración de los Derechos del Niño de 1959, recoge 10 principios, fue aprobada en el seno de las Naciones Unidas por voluntad propia y la CDN de 1989 ya es un documento que contiene 54 artículos y tuvo una larga gestación en la que participaron representantes nacionales, organismos no gubernamentales y otras entidades religiosas, cívicas o políticas, y promulgada por Naciones Unidas (CANTWELL, 1998; VERHELLEN, 1998; DETRICK, 1992). Por lo tanto, existen diferencias tanto en el contenido de los textos como en los agentes promotores.

El texto completo de la Declaración de Ginebra se puede consultar en: http://www.undocuments.net./gdrc1924.htm, la Declaración de los Derechos del Niño en http://www.un.org/cyberschoolbus/humanrights/resources/child.asp y la Convención sobre los Derechos del Niño en http://www.ohchr.org/en/professionalinterest/pages/crc.aspx. 


\subsection{Ante cualquier situación, los niños primero}

Los ámbitos en los cuales se articula el discurso dominante sobre los derechos del niño y que parecen mostrar una permanencia constante en los tres tratados son los siguientes: 1) Satisfacción de las necesidades básicas, 2) La familia, 3) Asistencia y protección en situaciones vulnerables y 4) Garantizar los derechos civiles y políticos. Además de estos ámbitos, cabe identificar tres derechos permanentes y que se van consolidando como principios inamovibles. Nos referimos a: 1) el derecho a la educación, 2) al principio de no discriminación y 3) al presupuesto moral relativo a los "niños primero", que actúa como un recurso retórico, sin mayor desarrollo normativo hasta la CDN de 1989 con el controvertido concepto de “interés superior del niño” . Es decir, se trata de un discurso de una arquitectura sencilla, donde los pilares dominantes continúan siendo dos: el cuidado de las necesidades básicas y el derecho a la protección, características que polarizan el discurso sobre la infancia.

Pasaremos a referirnos, en primer lugar, a estos tres últimos derechos, para centrarnos posteriormente en los cuatro ámbitos señalados. Por lo que respecta, al “interés superior del niño”, la base la encontramos en la redacción del principio III de la Declaración de Ginebra (1924). Así, vemos como hay una continuidad en la redacción de este principio, pasando de "el niño debe ser el primero en recibir ayuda en tiempo de peligro" (1924), a "el niño debe en todas circunstancias figurar entre los primeros que reciban protección y socorro" (1959). La CDN, en su artículo 3.1, convierte este concepto en principio transversal, quedando su redacción de la siguiente manera: "En todas las medidas concernientes a los niños que tomen las instituciones públicas o privadas de bienestar social, los tribunales, las autoridades administrativas o los órganos legislativos, una consideración primordial a que se atenderá será el interés superior del niño”.

La no discriminación aparece ya en la Declaración de 1924, no en el articulado, pero sí en su preámbulo, donde se afirma que los derechos que se reconocen están por encima de "toda consideración de raza, nacionalidad o credo". La redacción final de la Declaración de 1959, siguiendo la Declaración Universal de los Derechos Humanos de

\footnotetext{
† Observación General $n^{\circ} 5$ (2003): Medidas generales de aplicación de la Convención sobre los Derechos del Niño (artículos 4 y 42 y párrafo 6 del artículo 44) CRC/GC/2003/5.
} 

condición ya sea del propio niño o de su familia”. Este último motivo de no discriminación se refería sin duda a la inclusión de los niños nacidos fuera del matrimonio. Por supuesto, la CDN recogerá este principio en su artículo segundo, de acuerdo con todos los tratados de derechos humanos y lo hace de una forma muy amplia; incluyendo "los impedimentos físicos, el nacimiento y cualquier otra condición, de sus padres o de sus representantes legales", además de implicar a los Estados Partes en la garantía de esos derechos y la protección contra toda forma de discriminación (RODRÍGUEZ, 2006).

Finalmente, con respecto a la educación, se sustenta tanto en el derecho al acceso a la escuela como en el contenido de las enseñanzas, encaminadas al mantenimiento de la paz y a la ciudadanía. De esta manera, y ya desde la Declaración de Ginebra, se concibe que la educación ha de ser el mejor antídoto contra la discriminación, sobre todo combinando el desarrollo personal y el servicio a los otros. A partir de la Declaración de Derechos Humanos de 1948, este derecho se orientará hacia el desarrollo de "un espíritu de fraternidad y paz universales". Lo mismo hará la Declaración de 1959, donde queda perfectamente establecido el "espíritu de comprensión, tolerancia, amistad entre los pueblos, paz y fraternidad universal, y con plena conciencia de que debe consagrar sus energías y aptitudes al servicio de sus semejantes". Toda esta argumentación no puede ser olvidada cuando leemos el artículo 29 de la CDN, donde aparecen los objetivos de la educación: desarrollo de la personalidad, respeto a los derechos humanos; respeto a los padres, a la identidad cultural y valores nacionales y de otras civilizaciones; asunción de una vida responsable en una sociedad libre con respeto a la diversidad y, finalmente, respeto al medio ambiente natural. Por otra parte, la CDN, en el artículo 28 , fija el derecho a la educación de una forma que compromete a los Estados Partes a asegurar su disfrute (BEITER, 2006; TOMASEVSKI, 2006; DÁVILA y NAYA, 2011). Por lo tanto, estos tres derechos confirman un perfil donde se resalta la importancia de la educación, la no discriminación y la defensa de los niños y las niñas en cualquier situación. 


\subsection{Familia, protección y derechos civiles}

Por lo que respecta a los diferentes ámbitos que hemos señalado (necesidades, familia, protección y derechos civiles), la satisfacción de las necesidades básicas es, sin duda, un eje presente en todos los documentos. Es cierto que en los primeros textos tan solo se apunta la dirección por dónde deben ir estas atenciones, para llegar a 1989 a una concepción amplia y bien articulada. Así, en 1924, tan solo se menciona que "se debe dar a los niños los medios para su normal desarrollo, tanto material como espiritual”. En la Declaración de 1959 se recogen diversos aspectos del desarrollo moral, social, etc. y se añade que el disfrute de los mismos debe producirse en "condiciones de libertad y dignidad”; apareciendo por primera vez la mención al "interés superior del niño", como consideración fundamental a la hora de promulgar leyes.

En relación directa con el desarrollo armonioso de los niños y niñas, la familia será otro ámbito que irá adquiriendo una presencia cada vez mayor. Así, mientras en la Declaración de Ginebra no se dice nada al respecto, en los textos posteriores se matiza esta situación, señalando que "la sociedad y las autoridades públicas tendrán la obligación de cuidar a los niños sin familia", como recoge la Declaración de 1959. También se procurará no separar a los niños de corta edad de su madre, e incluso se prevé que, en casos de familias numerosas, el Estado conceda subsidios a las mismas. En la CDN, en contra de lo que algunas lecturas apresuradas manifestaron en un principio, la familia figura como uno de los ejes fundamentales, junto con el Estado para garantizar y proteger los derechos de los niños y niñas, como dice en su artículo 5, entre otros.

No obstante, tenemos que resaltar que donde los documentos adquieren mayor fuerza es en el ámbito de la asistencia y protección en situaciones vulnerables. En este sentido, los planos que cabe incluir en este ámbito son los relativos a los niños y niñas con necesidades especiales, la protección en casos de explotación y la asistencia y seguridad social. La Declaración de Ginebra, en su II principio, al decir que "el niño hambriento debe ser alimentado; el niño enfermo debe ser atendido; el niño deficiente debe ser estimulado; el niño desadaptado debe ser reeducado; y el huérfano y el abandonado deben ser recogidos y ayudados", señala de una forma amplia las posibilidades de este derecho de protección, que se irá depurando hasta la Declaración de 1959. Resulta 
ilustrativo el cambio de palabras que va sufriendo este derecho, de manera que casi podemos asistir a la propia evolución de los conceptos en relación con este tipo de población. Así, se pasa de “delincuente”, “deficiente”, “huérfano” o "abandonado” en 1924, a "desadaptado", "inadaptado" en 1948, y de aquí a "inadaptado física, mental o socialmente" para llegar a la Declaración de 1959, donde se habla de "el niño físicamente o mentalmente impedido o que sufra algún impedimento social”. Lo mismo ocurre si nos referimos a la protección con respecto a todo tipo de abandono, crueldad o explotación, donde la cuestión que subyace se refiere principalmente a la explotación laboral, como finalmente señala el principio IX de la declaración de 1959, recordando que "no deberá permitirse al niño trabajar antes de una edad mínima adecuada [... ] que pueda perjudicar su salud o educación".

Junto con estos dos planos, el poder beneficiarse de una seguridad y previsión social es otro aspecto que subyace en estos derechos de protección. La CDN le dedicará a todo este tipo de atenciones una serie de artículos relacionados con malos tratos, explotación laboral, tráfico de drogas, explotación sexual, venta o trata de niños, tortura y pena de muerte; así como la retención ilícita de niños, niños privados de medio familiar, adopción, niños refugiados, niños impedidos mental o físicamente, niños pertenecientes a minorías o poblaciones indígenas, conflictos armados, justicia del menor y reintegración social.

Finalmente, y con relación al reconocimiento de los derechos civiles y políticos, hay que recordar que éstos tendrán una entrada tardía en el campo de los derechos del niño y se incorporan como consecuencia de la Declaración Universal de Derechos Humanos de 1948. Así, en la Declaración de 1959 aparece, por primera vez, el derecho que les asiste a los niños a un nombre y una nacionalidad, derecho fundamental sin el cual no se pueden entender el resto de los derechos. No obstante, y como se ha señalado tantas veces, una de las novedades mayores de la CDN es la apertura a los derechos de autonomía que han dado lugar a una concepción diferente de los derechos del niño, pasando de ser objeto de protección a ser sujeto de derecho. En este sentido, estos derechos se especificarán no sólo en el de nombre y nacionalidad, sino también en los de libertad de expresión, de pensamiento, conciencia y religión, asociación, opinión del niño, protección a la vida 
privada, participación, de acuerdo con su capacidad y desarrollo (OCHAITA y ESPINOSA, 2004; GARIBO, 2004).

Por lo tanto, siguiendo el contenido de los tratados sobre derechos del niño, podemos apreciar que el discurso sobre la infancia durante el siglo XX mantiene una continuidad basada, sobre todo, en la defensa de dos ámbitos de derechos diferenciados: uno, referente a la satisfacción de necesidades básicas y protección y, otro, a los derechos de autonomía de los niños y niñas. De esta manera, podemos afirmar que se mantiene la continuidad de un discurso proteccionista de la infancia; cuya ruptura mayor se produjo en 1989 con el reconocimiento de los derechos civiles y políticos de los niños y niñas, sujetos ya de derecho. Esto supone una representación social e institucional caracterizada por los siguientes elementos: los niños son objetos de protección, que no pueden ser discriminados, con necesidades básicas que deben ser satisfechas, con derecho a una familia y con el reconocimiento de unos derechos civiles y libertades fundamentales. Estos últimos derechos son los más controvertidos, pues suponen la autonomía de la infancia y la participación. En este conjunto de derechos se fundamenta el nuevo paradigma de la infancia: los niños y niñas son sujetos de derecho.

\section{La representación de la infancia y el Comité de los Derechos del Niño}

Cuanto llevamos dicho sobre los fundamentos de los derechos del niño debemos insertarlo en una concepción que nos permita comprender la representación social e institucional que se ha ido construyendo alrededor de la infancia, ya que el conocimiento que tenemos de los niños y niñas en Occidente está mediatizado por la representación social que se tiene de la infancia. Es decir, existe una tesis fuerte que coincide fundamentalmente con lo que plantea Casas (2010, p. 18; 1998) cuando dice que "los miembros de la categoría social de los adultos hemos creado subcategorías de sujetos para poder seguir argumentando que hay seres que por encima de todo no pueden ser considerados 'iguales' a los 'ya adultos”'. En este sentido, a lo largo de las últimas décadas, las visiones que tenemos de la infancia han ido variando, pasando de una lógica resistente al cambio, caracterizada por temas como "los niños están en proceso de 
niños controlan tecnologías audiovisuales", “los niños tienen responsabilidades y competencias", "los niños contribuyen productivamente a su sociedad" o "los valores son compartidos". Por lo tanto, la construcción social de la infancia solamente puede explicarse desde la contextualización histórica de esos argumentos que conforman diferentes representaciones de la infancia, construidas por los adultos. La infancia es "un espacio simbólico desde el cual los adultos imaginan el futuro y crean utopías políticas, económicas, materiales, sociales o culturales" (SOSENSKI, 2012, p. 191).

Al margen de los planteamientos ideológicos, la representación social de la infancia, al igual que otras representaciones sociales, consiste precisamente en “condicionar e influir las prácticas, actitudes y comportamientos de las personas y de las instituciones" (SÁNCHEZ, 2010, p. 100). Por otra parte, dentro de las disciplinas académicas, los estudios sobre la infancia han ido adquiriendo una importancia relevante, ofreciendo una imagen complementaria de los niños y niñas. En un congreso, celebrado en París en mayo de 2013 se planteó una pregunta que todavía no está resuelta: A quelle discipline appartiennent les enfants? [¿A qué disciplina pertenecen los niños?]. No se trataba de una pregunta retórica, sino más bien de poner sobre la mesa cuestiones de delimitación disciplinar entre las diferentes ciencias sociales, a fin de aclarar el campo más pertinente para estudiar la infancia en su diversidad, lo que podemos denominar Children's Sudies. Hay que resaltar que en el proceso de construcción de sentido y de la categoría de infancia, el discurso del "saber psi” ha sido determinante (LLOBET, 2014). Por otra parte, y desde la perspectiva histórica, la obra reciente de Susana Sosenski y Elena Jackson Albarán (2012) da cumplida cuenta de la representación de la infancia en diversos contextos geográficos y cronológicos en la historia de América Latina. Todos estos planteamientos son el marco en el cual podemos insertar la labor de las políticas públicas alrededor de la infancia o los posicionamientos institucionales de organismos como Unicef o el Comité de los Derechos del Niño. 


\subsection{El Comité de los Derechos del Niño: un nuevo perfil para la infancia}

En el contexto que estamos analizando, la representación de la infancia construida por el Comité de los Derechos del Niño§ tiene un interés singular, ya que, dentro del sistema de Naciones Unidas, este organismo es el encargado del seguimiento e interpretación de la CDN. El Comité está formado por 18 expertos internacionales, nombrados por la Asamblea de Naciones Unidas. Desde 1991 el Comité ha emitido observaciones y recomendaciones a los diversos Estados después de haber analizado los informes que, periódicamente, tienen que presentar, como se señala en los artículos 43 a 45 de la CDN. Por lo tanto, se trata de una voz autorizada que conoce de primera mano la situación de la infancia en el mundo (CARDONA, 2012).

El trabajo del Comité es complejo, pues debe examinar los informes de los Estados Partes sobre la implementación de la CDN, así como los relativos a los protocolos facultativos y los informes alternativos de las diferentes ONGs. Los miembros del Comité, además del trabajo señalado, realizan sesiones técnicas internas previas a cada sesión que suelen tener como resultado final la publicación de Observaciones Generales sobre la aplicación de determinados artículos de la CDN en las que el Comité interpreta su contenido (CARDONA, 2012). Para conocer el proceso de construcción de la representación de la infancia a través del Comité podemos analizar estas Observaciones Generales. Hasta la actualidad, el Comité ha elaborado 17 Observaciones Generales, relativas tanto a cuestiones sobre las medidas de aplicación de la CDN, como a derechos concretos, como puede observarse por los títulos de las mismas:

\begin{tabular}{c|c|l}
\hline $\mathbf{N}^{\circ}$ & Año & Tema desarrollado \\
\hline 17 & 2013 & $\begin{array}{l}\text { Derecho del niño al descanso, el esparcimiento, el juego, las actividades } \\
\text { recreativas, la vida cultural y las artes (artículo 31) }\end{array}$ \\
\hline 16 & 2013 & $\begin{array}{l}\text { Obligaciones del Estado en relación con el impacto del sector empresarial en los } \\
\text { derechos del niño }\end{array}$ \\
\hline 15 & 2013 & Derecho del niño al disfrute del más alto nivel posible de salud (artículo 24) \\
\hline
\end{tabular}

\footnotetext{
$\S$ Se puede consultar información sobre el Comité de los Derechos del Niño, Observaciones Generales, etc. en la siguiente dirección http://www.ohchr.org/EN/HRBodies/CRC/Pages/CRCIndex.aspx
} 


\begin{tabular}{|c|c|c|}
\hline 14 & 2013 & $\begin{array}{l}\text { Derecho del niño a que su interés superior sea una consideración primordial } \\
\text { (artículo 3, párrafo 1) }\end{array}$ \\
\hline 13 & 2011 & Derecho del niño a no ser objeto de ninguna forma de violencia \\
\hline 12 & 2009 & Derecho del niño a ser escuchado \\
\hline 11 & 2009 & Los niños indígenas y sus derechos en virtud de la Convención \\
\hline 10 & 2007 & Los derechos del niño en la justicia de menores \\
\hline 9 & 2006 & Los derechos de los niños con discapacidad \\
\hline 8 & 2006 & $\begin{array}{l}\text { El derecho del niño a la protección contra los castigos corporales y otras formas } \\
\text { de castigo crueles o degradantes (artículo 19, párrafo } 2 \text { del artículo } 28 \text { y artículo } \\
\text { 37, entre otros) }\end{array}$ \\
\hline 7 & 2005 & Realización de los derechos del niño en la primera infancia \\
\hline 6 & 2005 & $\begin{array}{l}\text { Trato de los menores no acompañados y separados de su familia fuera de su } \\
\text { país de origen }\end{array}$ \\
\hline 5 & 2003 & $\begin{array}{l}\text { Medidas generales de aplicación de la Convención sobre los Derechos del Niño } \\
\text { (artículos } 4 \text { y } 42 \text { y párrafo } 6 \text { del artículo 44) }\end{array}$ \\
\hline 4 & 2003 & $\begin{array}{l}\text { La salud y el desarrollo de los adolescentes en el contexto de la Convención } \\
\text { sobre los Derechos del Niño }\end{array}$ \\
\hline 3 & 2003 & El VIH/SIDA y los derechos del niño \\
\hline 2 & 2002 & $\begin{array}{l}\text { El papel de las instituciones nacionales independientes de derechos humanos en } \\
\text { la promoción y protección de los derechos del niño }\end{array}$ \\
\hline 1 & 2001 & Propósitos de la Educación \\
\hline
\end{tabular}

En estas 17 Observaciones Generales puede apreciarse que el perfil de la infancia es caleidoscópico, en tanto que se abre al análisis de un conjunto de derechos amplio y, en general, ofrece muchos matices provenientes de los distintos campos de trabajo de los miembros del Comité. Téngase en cuenta que el Comité es el que interpreta los derechos recogidos en la CDN y que esa interpretación viene mediatizada por la experiencia acumulada a lo largo del tiempo. También es cierto que los informes se han ido estandarizando y sintetizando a lo largo del tiempo, ofreciendo una imagen de una infancia universal, al margen de los informes de los países, que muestran realidades muy contrastadas de la situación de los niños y niñas en el mundo. En este sentido, los miembros del Comité pueden matizar mucho mejor las diferentes infancias y ofrecer una imagen más adecuada a la realidad. Con la mera enumeración del título de las Observaciones Generales, se puede ver que, en contraste con la visión del Unicef, a la que 

compleja, en tanto que atiende a un amplio elenco de derechos del niño.

A diferencia de lo que hemos observado sobre la representación institucional de Unicef (DÁVILA y NAYA, 2015), la diversidad de temáticas abordadas por el Comité es más amplia y adecuada a la CDN. Así, pues, confrontando los Estados Mundiales de la Infancia y las Observaciones Generales y las fechas en las que se han publicado, se aprecia que se han tratado temas comunes en los siguientes casos: educación (COMITÉ DE LOS DERECHOS DEL NIÑO, 2001 y UNICEF, 1999); Personas con discapacidad (COMITÉ DE LOS DERECHOS DEL NIÑO, 2006 y UNICEF, 2013); Primera infancia (COMITÉ DE LOS DERECHOS DEL NIÑO, 2005 y UNICEF, 2001); Salud y supervivencia (COMITÉ DE LOS DERECHOS DEL NIÑO, 2003 y 2013 y UNICEF, 2009, 2008, 1998, 1994, 1993, 1989, 1988, 1987, 1986, 1985, 1983, 1982); Participación (COMITÉ DE LOS DERECHOS DEL NIÑO, 2009 y UNICEF, 2003). Por lo tanto, ya en una primera lectura, se puede manifestar que el Comité tiene una perspectiva más amplia y construye una representación de la infancia con un perfil mucho más complejo y donde cabe apreciar una variedad de temas mucho mayor. En estas observaciones, se aprecia una menor reiteración de temas relacionados con la salud y supervivencia, tema muy presente en los informes del Unicef. Asimismo, el Comité ha dedicado atención a tres de los cuatro principios generales de la CDN (participación, interés superior del niño y supervivencia), pero no ha escrito ninguna observación sobre la no discriminación. No obstante, se entiende que cuando el Comité se refiere a la situación de los niños/as indígenas o a los niños/as con discapacidad, o a otros derechos lo está haciendo desde esta óptica de la no discriminación.

No obstante, también se aprecian algunas lagunas o ausencias, sobre todo en el campo del trabajo infantil o de la sexualidad (MALON, 2012). Es decir, dos derechos que podrían sustentar un discurso emancipador de la infancia, en tanto que autonomía personal, pero que están ausentes, tanto de la imagen que ofrece el Comité como de la de Unicef. Es cierto que la existencia del "Protocolo facultativo relativo a la venta de niños, la prostitución infantil y la utilización de niños en la pornografía” de 2000 puede 
hacer derivar la temática de la sexualidad hacia las recomendaciones que el propio Comité tiene que redactar en base a los informes de los Estados Partes que han ratificado este protocolo. No obstante, ello no es obstáculo para que el Comité pueda redactar observaciones generales sobre esta temática. Por lo tanto, la representación institucional de la infancia del Comité ofrece un perfil más sólido con respecto a la consideración de los niños como sujetos de derechos, con la mayoría de matices que caben en esta concepción. La ruptura del discurso proteccionista no se ha producido todavía, aunque ya no sea hegemónico (CORDERO, 2012).

\section{La implementación de la CDN en América Latina}

Para poder mostrar el perfil de la infancia en América Latina, hemos tomado un corpus documental consistente en todas las Observaciones finales emitidas por el Comité de los Derechos del Niño a los informes de seguimiento de los Estados Partes de la región desde 1991 hasta 2013. Este periodo seleccionado cubre prácticamente desde el inicio de las labores del Comité hasta la actualidad. Esta coincidencia nos permite cerrar un periodo muy rico en acontecimientos en América Latina y en la evolución e implementación de la CDN. Una vez conformado el corpus documental hemos procedido al vaciado de toda esta voluminosa información, hemos elaborado una serie de categorías y hemos seleccionado un conjunto de dimensiones que configuran un conjunto de derechos que marcan un perfil definido de la infancia y que, a los efectos de este trabajo, es elocuente para poder explicar la representación social de la infancia que estamos estudiando.

Entendemos que esta información, obtenida de los informes, puede o no estar contrastada con la realidad de los niños y niñas en los países respectivos, o de las diferentes situaciones por las que atraviesan, a pesar de la riqueza de información con la que muchos países acompañan sus informes. No obstante, para conocer esa realidad hay una abundante bibliografía. Un buen recurso actual, y desde la perspectiva de los derechos del niño, lo podemos encontrar en la obra de Cepal y Unicef (2014), donde se presenta un estado de la cuestión después de 25 años de vigencia de la CDN en América Latina. No obstante, este trabajo tropieza con los mismos mitos que tantas veces se han 
identidad [... también es cierto que persisten desigualdades en el acceso y ejercicio de estos derechos para ciertos grupos de niños y niñas" (CEPAL/UNICEF, 2014, p. 5). Es decir, se trata de un discurso muy presente también en los informes del Comité que vamos a analizar y que se sustancia en una afirmación positiva respecto al plano legislativo o normativo, pero ante la que persiste una realidad en la que son palpables las situaciones de vulnerabilidad.

Cuanto llevamos dicho, debe entenderse como parte complementaria del análisis que hemos realizado. Asimismo hay que resaltar los trazos sobre los que se está dibujando el perfil de la infancia, siguiendo el marco de la CDN. Nuestro análisis coincide, en muchos aspectos, con la realidad que muestra este informe y ratifica la representación institucional de la infancia por parte del Comité.

Con respecto a la implementación de la CDN, y al igual que la mayoría de países occidentales, todos los países de América Latina firmaron y ratificaron la CDN en los años inmediatamente posteriores a su aprobación en 1989. Los Estados de América Latina han seguido, en la mayoría de los casos, el proceso de implementación de la CDN en sus legislaciones nacionales, actualizando los Códigos de la Niñez (DÁVILA y NAYA, 2011, pp. 149-194).

Antes del año 2011, todos los países de América Latina habían presentado, como mínimo, un informe al Comité. En 2012 y 2013 ningún país de la región tuvo que hacerlo (DÁVILA y NAYA, 2011) y en 2015 lo han hecho a República Dominicana, Colombia y Uruguay. Con lo cual, a partir de 2015, se ha vuelto a abrir un nuevo periodo, en el que podremos conocer los cambios en la situación de los niños, niñas y adolescentes a través de la información vertida en los informes y las observaciones del Comité. Por lo tanto, existe una cierta unidad y homogeneidad, en cuanto al periodo de los informes que hemos analizado en el periodo 1992-2013. 
Tabla 1. Fecha de entrega de informes sobre la CDN de los países de América Latina

\begin{tabular}{|c|c|c|c|c|}
\hline & \multicolumn{4}{|c|}{ Informes periódicos } \\
\hline & \multirow{2}{*}{\begin{tabular}{|c|}
$\mathbf{1}^{\circ}$ \\
1993 \\
\end{tabular}} & \multirow{2}{*}{$\begin{array}{c}\mathbf{2}^{\circ} \\
1999\end{array}$} & $3^{\circ}$ & $4^{\circ}$ \\
\hline Argentina & & & \multicolumn{2}{|c|}{$20083^{\circ}$ y $4^{\circ}$ refundidos } \\
\hline Bolivia & 1992 & 1997 & 2002 & 2008 \\
\hline Brasil & 2003 & \multicolumn{3}{|c|}{$20122^{\circ}, 3^{\circ}$ y $4^{\circ}$ refundidos } \\
\hline Chile & 1993 & 1999 & 2005 & $20124^{\circ}$ y $5^{\circ}$ refundidos \\
\hline Colombia & 1993 & 1998 & 2004 & $20114^{\circ}$ y $5^{\circ}$ refundidos \\
\hline Costa Rica & 1992 & 1998 & 2003 & 2009 \\
\hline Cuba & 1995 & 2009 & \multicolumn{2}{|c|}{ Debe entregar $3^{\circ}$ y $4^{\circ}$ refundidos en 2017} \\
\hline Ecuador & 1996 & \multicolumn{2}{|c|}{$20032^{\circ}$ y $3^{\circ}$ refundidos } & 2008 \\
\hline El Salvador & 1992 & 2002 & \multicolumn{2}{|c|}{$20073^{\circ}$ y $4^{\circ}$ refundidos } \\
\hline Guatemala & 1995 & 1998 & $\begin{array}{c}2003 y \\
2006\end{array}$ & $20083^{\circ}$ y $4^{\circ}$ refundidos \\
\hline Honduras & 1993 & 1997 & 2006 & $20134^{\circ}$ y $5^{\circ}$ refundidos \\
\hline México & 1992 & 1998 & 2004 & $20124^{\circ}$ y $5^{\circ}$ refundidos \\
\hline Nicaragua & 1994 & 1997 & 2003 & 2008 \\
\hline Panamá & 1995 & 2002 & \multicolumn{2}{|c|}{$20093^{\circ}$ y $4^{\circ}$ refundidos } \\
\hline Paraguay & $\begin{array}{c}1993 \text { y } \\
1996\end{array}$ & 1998 & 2008 & $20084^{\circ} y^{\circ}$ \\
\hline Perú & 1992 & 1998 & 2004 & $20134^{\circ}$ y $5^{\circ}$ refundidos \\
\hline $\begin{array}{l}\text { República } \\
\text { Dominicana }\end{array}$ & 1998 & 2007 & \multicolumn{2}{|c|}{$20113^{\circ}, 4^{\circ}$ y $5^{\circ}$ refundidos } \\
\hline Uruguay & 1995 & 2006 & \multicolumn{2}{|c|}{$20123^{\circ}, 4^{\circ}$ y $5^{\circ}$ refundidos } \\
\hline Venezuela & 1997 & 2006 & \multicolumn{2}{|c|}{$20123^{\circ}$ y $4^{\circ}$ refundidos } \\
\hline
\end{tabular}

Fuente: Oficina del Alto Comisionado para los Derechos Humanos. Elaboración propia.

Con la ratificación de la CDN se entró en una nueva situación en el enfoque de los derechos humanos que conlleva la defensa de los derechos de los niños y fue necesaria la modificación de la doctrina jurídica dominante en los años noventa en América Latina, todo lo cual repercutió en la implementación de la CDN en los diferentes países y en la 

proceso de reformas legislativas, la aceptación de la CDN supuso una "ruptura" con el pasado, ya que su implementación incorporó una nueva concepción, regida por la defensa de los derechos del niño, en un contexto de renovación democrática. A partir de estos cambios, se aprecia una mayor implicación de los Estados en sus obligaciones y en la garantía de sus derechos fundamentales, adecuándolos a los tratados internacionales, tanto del sistema interamericano como internacional. Desde esta fecha, "ya nadie discute en América Latina que la protección de la niñez debe plantearse a partir de un enfoque de ciudadanía y de protección de los derechos humanos de niños y niñas" (BELOFF, 2008).

\section{El perfil de la infancia en América Latina}

El análisis que estamos realizando se centra en un conjunto de derechos que construyen un perfil que representa muy bien la imagen de la infancia en América Latina. De todos los derechos reconocidos, los que menor atención reciben, o han recibido, a lo largo del tiempo son los relacionados con los derechos civiles, excepto el de la identidad. Por lo tanto, persiste la idea de que los derechos civiles y de participación, que son los que fundamentarían una concepción de los niños como sujetos de derecho, no tienen una importancia mayor por parte de los países. Por otra parte, hemos excluido de este análisis dos derechos que nos parecen fundamentales: el derecho a la vida y a la supervivencia y el derecho a la educación. El primero de ellos, además, está relacionado con otros derechos como el logro de un nivel de vida digno, derecho a la salud, a la seguridad social, a la alimentación, etc. El segundo es, también, un derecho presente en muchos artículos de la CDN. Por lo tanto, se trata de dos límites impuestos de manera explícita, evitando utilizar un criterio arbitrario, como expresamente manifiestan Cepal/Unicef (2014), cuya base argumentativa reside, de alguna manera, en un complejo análisis de factores que influyen en la aplicación y cumplimiento de la CDN, desde una visión de políticas públicas y su influencia en la situación de la infancia. El resultado obtenido puede resumirse en la existencia de cinco ámbitos de preocupación por parte de dicho Comité: 1) Falta de 

sobre los códigos de la niñez y la CDN, además de la falta formación de los profesionales. Por su parte, la Red Latinoamericana y Caribeña para la defensa de los Derechos de los Niños y Adolescentes ha realizado un balance, estableciendo tres ámbitos de análisis: 1) avances vinculados a la $C D N ; 2$ ) retrocesos que afectan a los derechos del niño; y 3 ) principales problemas vinculados al cumplimiento de los derechos del niño (REDLAMYC, 2009).

Por lo tanto, la representación que ofrecemos, a la luz de las observaciones del Comité, se basa en dos conjuntos de derechos: por una parte, el derecho a una vida libre de violencia, es decir, digna y adecuada a las necesidades de los niños, niñas y adolescentes y, por otra, el derecho a una infancia sin discriminación. Con el análisis de estos derechos se recoge, en trazos generales, un perfil de la infancia bastante habitual en América Latina. No obstante, tenemos que considerar que esa imagen no es monolítica y que ofrece matices que han ido variando en cada uno de los países a lo largo de los últimos 25 años. Se trata de una imagen fotográfica de los momentos en los que se presentaron los informes a lo largo de estos años y cuya evolución tendrá que explicarse a partir de variables a menudo no presente en los informes.

Una evidencia que hemos podido constatar al leer las observaciones del Comité es que, debido a la narración que realiza, los argumentos tienen una estructura permanente. Por una parte, comienza manifestando la situación en que se encuentra el país en cada uno de los ámbitos que analiza, para, a continuación, realizar las observaciones que considera oportunas, relacionadas, en general, con las carencias o violaciones de derechos que detecta y, finalmente, recomienda la necesidad de adaptarse a los criterios utilizados por el Comité, de acuerdo con las observaciones generales que él mismo realiza y los principios básicos de la CDN. Por lo tanto, hace un diagnóstico y realiza una recomendación. 


\subsection{Derecho a una vida libre de violencia, digna y adecuada}

El conjunto de cuestiones que hemos incluido en este apartado abarca diversos derechos que tienen dependencia diferente en cuanto a los contenidos generales de la CDN, algunos de ellos están relacionados con la salud, como son el embarazo precoz, otros con la justicia de menores y otros con diversos tipos de explotación. El criterio que rige este apartado es que, de alguna manera, configuran una imagen en la que los niños, niñas y adolescentes en América Latina que se ven sometidos a diversos tipos de violencia o debido a las situaciones vulnerables que impiden el disfrute de una vida digna, adecuada y acorde a los principios de la CDN.

Un elemento relevante en la imagen de la infancia en América Latina es la persistencia en el tiempo de malos tratos, violencia, abusos y abandono de menores de 15 años (CEPAL/UNICEF, 2014, p. 36). Esta situación aparece en la mayoría de las observaciones finales del Comité a los Estados Partes, con diversas denominaciones como violencia contra los niños, malos tratos, violencia familiar, castigo corporal, etc. En la mayoría de los casos, se constata que, a pesar la existencia de legislaciones contra este tipo de violencia, como ocurre en Argentina, Bolivia, Brasil, Ecuador, Paraguay, Perú y Uruguay, el hecho es que este tipo de comportamientos persiste. Así se observa, por ejemplo, como en Bolivia (2009) ** y a pesar de que la constitución prohíbe todo tipo de violencia contra los niños, el Comité sigue preocupado por la persistencia de castigos corporales en los entornos de acogida institucional. También se constata la existencia de abusos físicos y sexuales o torturas en centros de detención en Colombia (2000). Se aprecia una cierta mejoría en este aspecto en los casos de Costa Rica, Ecuador, Guatemala, Nicaragua o Venezuela. La constitución de Ecuador de 2009 prohíbe también todo tipo de violencia contra los niños. En Nicaragua, tanto la constitución como el código de la niñez excluyen todo tipo de malos tratos y en Venezuela se constata la existencia de programas sobre la violencia contra los niños. No obstante, el esfuerzo mayor por parte de los países es la persistencia de este tipo de malos tratos en la sociedad y sus dificultades para erradicarlo, ya que se considera un hecho aceptable

\footnotetext{
** En este apartado el año que aparece entre paréntesis se corresponde con el año de redacción de las observaciones por parte del Comité de los Derechos del Niño.
} 
socialmente. Así, los malos tratos están muy extendidos en la sociedad (ECLAC y UNICEF, 2009), según se desprende también de los informes presentados ante el Comité.

Los temas que tratamos a continuación afectan a unas poblaciones vulnerables, bien sea por tratarse de niños en conflicto con la justicia, explotación sexual, abandono o trabajo infantil. El ámbito de los niños en conflicto con la justicia, a pesar de la incorporación de medidas garantistas en los sistemas judiciales en los últimos años, es también uno de los elementos que ofrecen una imagen negativa de los procedimientos que se siguen con los niños sometidos al mismo. Así, mientras la CDN es partidaria de tomar medidas socioeducativas que favorezcan la integración de los niños en la sociedad, lo cierto es que estas medidas no son las predominantes, ya que en muchos casos se opta por el internamiento o la privación de libertad. Por lo tanto, el perfil que se recoge en las observaciones del Comité tiene trazos oscuros en cuanto que los niños han compartido en algunos casos espacio de internamiento con adultos. Así, también preocupa que las medidas de internamiento aplicadas a los menores de 18 años sean similares a los adultos, como ocurre en el caso de Chile (2005), el descenso de la edad de responsabilidad penal de 14 a 12 años en Paraguay (2011) o la inexistencia de una justicia especializada para menores en Uruguay (2006) o Venezuela (2007). Toda esta situación refleja imágenes “estereotipadas y estigmatizantes" de los delincuentes juveniles en los medios de comunicación, como se observa en Uruguay (2006).

Con respecto a la explotación sexual, ya hemos señalado la existencia de un Protocolo Facultativo que exige un seguimiento específico en el propio Comité. A pesar de ello también encontramos información relevante en las observaciones a los informes periódicos de los países sobre el seguimiento de la CDN, tal es así que, en muchos casos, se constata la alta incidencia de la explotación sexual. No obstante, en sentido positivo, hay que constatar la preocupación que muestran los países por erradicar este tipo de prácticas, así puede apreciarse que, en la mayoría de los países, hay medidas legislativas o penales que están incidiendo en los efectos de este tipo de explotación (Costa Rica, Ecuador, El Salvador, Guatemala, Honduras, Panamá o Paraguay). En cambio, en otros países, como México, Nicaragua, Perú, República Dominicana o Uruguay, no parece que las medidas tomadas hayan surtido efecto, especialmente en estos dos últimos países, 
con respecto al turismo y a la explotación sexual con fines comerciales. Sorprende la persistencia en Bolivia (2009) de niños indígenas que son víctimas de estos abusos.

Otro tipo de explotación, muy extendido en América Latina, es el trabajo infantil (CEPAL/UNICEF, 2009). Se trata de un tema polémico, en tanto que muchas veces se juzga este tipo de trabajo desde la visión universal de la infancia, en la cual los niños y niñas tendrían que estar libres del trabajo hasta una determinada edad. No obstante, también somos conscientes de que los niños trabajadores tienen una visión muy diferente, reclamando su justo reconocimiento. En algún sentido, si este trabajo es digno, puede ser una situación emancipatoria para la infancia (CORDERO, 2012). Sabemos también que a lo largo de la historia el trabajo infantil ha estado presente en muchos espacios sociales, tanto domésticos como en la industria y/o servicios (SOSENSKI, 2012). En los informes, se constata el intento de armonizar la finalización de la escolaridad obligatoria con la edad mínima para incorporarse al mercado de trabajo, aunque no siempre se lleve a cabo. También son de resaltar los programas y cambios legislativos para impedir la realización de trabajos duros y peligrosos. En este sentido, se aprecia la mejoría de la situación en países como Colombia, Costa Rica, Ecuador, El Salvador, Honduras, Nicaragua, Paraguay, Perú o Venezuela. En cambio, la situación parece persistir en Chile (2005), Panamá (2011), República Dominicana (2007) o Uruguay (2006) o incluso empeorar, como ocurre en México (2005). Por supuesto, la causa de la existencia del trabajo infantil, como se argumenta en los propios informes, es la persistencia de la pobreza infantil. El caso de Bolivia (1993 y 2009) vuelve a ser llamativo ya que los niños y niñas indígenas son las principales víctimas del trabajo infantil.

Finalmente, un tipo de exclusión social y educativa muy presente entre las adolescentes de América Latina es la persistencia del embarazo precoz (CEPAL/UNICEF, 2007). Es un tema que afecta a la salud de las adolescentes y que, como se detecta en muchas ocasiones, es debido a dos causas: la ausencia de políticas educativas encaminadas a una salud reproductiva adecuada y, por otra, a las políticas contrarias a la interrupción del embarazo vigentes en muchos países, que ocasionan numerosos abortos clandestinos, además de mortalidad materna. En la mayoría de los países se hace mención a las altas tasas de embarazo precoz (Bolivia (2009), Brasil (2003), Colombia (2005), Costa 
Rica (1993, 1998, 2004); Guatemala (2009); Honduras (2006); Perú (2005) o República Dominicana (2007)). Llaman la atención los casos de Nicaragua y Venezuela por el aumento de mortalidad de madres adolescentes provocado por la realización de abortos clandestinos o a causa de procedimientos peligrosos. En sentido positivo, el Comité “celebra” la distribución universal y gratuita de anticonceptivos en Argentina (2010), así como la puesta en marcha de planes de salud para la adolescencia en Costa Rica, Ecuador, Honduras, México o Paraguay (SALINAS, 2014).

\subsection{Derecho a una infancia sin discriminación}

Como ya hemos señalado, la no discriminación es un principio básico transversal en la CDN. Los dos colectivos, además del de las niñas que no hemos tratado específicamente, que sufren una mayor discriminación son el de los niños y niñas con discapacidad y el de los indígenas (CEPAL/UNICEF, 2013a, 2013b). No se puede afirmar, a través de los informes, que estos dos colectivos estén, además, libres de situaciones de violencia o de maltrato, debido a su vulnerabilidad. Es posible que, en algunos casos, también sea así, pero, de cualquier manera, lo que nos interesa resalta es la situación de discriminación que sufren a diversos niveles, tanto sociales, económicos, como educativos. Es cierto que, a lo largo de estos 25 años, la situación de estos dos colectivos ha mejorado, debido a cambios legislativos y a la introducción de un concepto nuevo, como es el de la "inclusión social y educativa”. Sin embargo, todavía persisten situaciones de discriminación.

Al igual que ocurre en Europa (DÁVILA y NAYA, 2009) y en América Latina (DÁVILA y NAYA, 2011), las personas con discapacidad suelen ser víctimas de discriminación económica, educativa, sanitaria, social, etc. que dificulta el acceso, en igualdad de condiciones, a los servicios disponibles. Un ámbito en el que se aprecia mayor preocupación es el relativo a la integración escolar, pues se entiende que el acceso a una educación de calidad repercute en el disfrute del resto de derechos. No obstante, también se registra en estos años la falta de integración en las escuelas y en la sociedad (Brasil (2003), El Salvador (2009), Nicaragua (2004), República Dominicana (2007) o 
Uruguay (2006)). Como elemento positivo, se constata la existencia de consejos y leyes que favorecerían esta integración, aunque no se plasme en la realidad, como ocurre en El Salvador (2009), Honduras (2006), Nicaragua (2010), Paraguay (2001), Perú (2005) o República Dominicana (1999). En general, el Comité se felicita por la existencia de una legislación favorable al reconocimiento de los derechos de los niños y niñas con discapacidad, pero, a la vez, constata las dificultades de llevar a cabo las medidas propuestas, en general tendentes a facilitar el acceso a los servicios públicos. En concreto, en el campo de la educación, son muchas las dificultades que suponen llevar a cabo una educación inclusiva.

El segundo colectivo que sufre mayor discriminación es el de los niños y niñas indígenas, discriminación mayor, en muchos casos, si se compara con el colectivo afrodescendiente, en los países en los que existe esta población, como, por ejemplo, es el caso de Colombia. Por lo tanto, podría ampliarse el concepto de minoría indígena u originaria al de minorías étnicas, aunque en algunos casos puedan llegar a ser hasta la mayoría de la población, como ocurre con Bolivia. Al igual que ocurre con el colectivo anterior, en los últimos años, los diferentes países han tomado medidas para incorporar en sus legislaciones los derechos de estas minorías (Bolivia, Brasil, Colombia, Costa Rica, Ecuador, México, Paraguay y Venezuela). En general, se trata de derechos que tienen que ver con la sanidad, la justicia y la educación. Los casos más favorables al respeto de los derechos de este colectivo son el de Bolivia y el de Ecuador, al definirse como estados plurinacionales, reconociendo el valor positivo de muchos principios indígenas en sus propias constituciones, el ejemplo del "Buen vivir", en el caso de Ecuador, es paradigmático. También el fomento de la educación intercultural bilingüe es otro de los elementos que favorecen un mayor reconocimiento de los derechos de estos colectivos en muchos países de la región. En contra de esta posición, vemos que Chile (2005) todavía no había incorporado a su constitución el reconocimiento a los pueblos indígenas. El Salvador también sufre una situación contradictoria en cuanto a la invisibilidad cultural de la población indígena y la falta de oportunidades para una educación intercultural bilingüe. Lo mismo ocurre con Guatemala, Honduras y Nicaragua. 


\section{Conclusiones}

La representación social de la infancia es un tema que ha estado presente a lo largo del siglo XX, sobre todo desde las instituciones que han cuidado de la protección y defensa de los derechos del niño. Para comprender cómo ha evolucionado esta visión en América Latina nos ha interesado situar un marco histórico que nos permita registrar los trazos más relevantes de esa representación. En este sentido, hemos analizado la representación de la infancia a través de los tres tratados de derechos del niño aprobados a lo largo del siglo XX. La representación institucional que se aprecia en dichos tratados tiene aspectos claroscuros que se refieren a la consideración de que la no discriminación y el interés superior del niño son los aspectos más relevantes de su concepción. Asimismo, se aprecia una visión de la infancia que atraviesa situaciones de vulnerabilidad, promoviendo políticas públicas que, a través de la protección, la ayuda y todo tipo de derechos, mitiguen una visión negativa de los niños con necesidades económicas, sociales, culturales y educativas. Por lo tanto, en los tratados sobre derechos de los niños, la imagen es ambivalente, en tanto que se demandan unos derechos, pero se constata una realidad de una infancia necesitada de protección.

Como continuación de esta imagen, representada por los tratados internacionales, el análisis presentado en este trabajo se ha centrado más en la representación de la infancia en América Latina a través de la construcción que, en sus informes, realiza el Comité de los Derechos del Niño. El perfil de la infancia en América Latina, a partir de los informes del Comité, está caracterizado por la falta de armonización entre la CDN y la legislación nacional, la preocupación por la indefinición de los principios generales de la CDN; la persistencia de malos tratos, abusos y castigo corporal; el abuso de la privación de libertad en la justicia juvenil, y la escasa información sobre los códigos de la niñez y la CDN, además de la falta formación de los profesionales. No obstante, en esta imagen claroscura de la infancia los aspectos que más interesan resaltar, con respecto a su representación institucional, son aquellos que tienen que ver con un perfil en el que los niños y niñas queden libres de sufrir cualquier tipo de violencia (malos tratos, abandono, abusos, castigos corporales, trabajo infantil, etc.) que parecen estar anclados en algunos países de la región. También son de resaltar las situaciones de discriminación que, en 
muchos países de América Latina, sufren dos colectivos de niños: los pertenecientes a poblaciones originarias o indígenas y los que sufren algún tipo de discapacidad.

La representación de esta infancia ha ido variando a lo largo de los últimos 25 años, ya que, en algunos casos, se han observado ciertos progresos en la situación de la infancia y, en otros, a pesar de que el Comité de los Derechos del Niño recomendaba cambios en las políticas públicas, lo cierto es que se aprecia una continuidad en esa imagen. Las razones de esta evolución o continuidad tienen diversas explicaciones, unas son de tipo contextual (cambios políticos, económicos o sociales) y otras debido a la incidencia de las políticas de protección de la infancia. Por lo tanto, cabría pensar que, en este segundo caso, las recomendaciones del Comité han cumplido la función de impulsar políticas públicas concretas que hayan servido para mejorar la situación de la infancia y, consecuentemente, cambiar la representación que de ella se tiene.

Por lo tanto, en la amplia amalgama posible de representaciones sobre la infancia, la elaborada por el Comité de los Derechos del Niño ofrece un perfil coherente con la CDN, y que ha pasado a convertirse en universal y hegemónico. Así pues, mientras en América Latina la implementación de los derechos del niño ha seguido algunos vericuetos adaptados a la realidad de la región, el Comité de los Derechos del Niño ha optado por mantener una representación universal y contextualizada sobre la infancia, incidiendo en aspectos novedosos que aportó, en su momento, la CDN y que están relacionados con la concepción de que los niños, niñas y adolescentes son sujetos de derecho.

La aceptación de ese discurso hegemónico en el plano legislativo es evidente, aunque se pueden constatar unas brechas importantes en la implementación normativa y práctica. A través de los informes elaborados por dicho Comité sobre la implementación de la CDN en América Latina se representa una infancia víctima de malos tratos, abusos y castigos corporales y de privación de libertad en los casos de conflicto con la justicia. Asimismo, el contraste de estas representaciones resulta positivo para poder constatar las dificultades que tiene el discurso hegemónico de la infancia y la realidad particular de cada uno de los países de América Latina. 


\section{Bibliografía}

BARDET, Jean Pierre; LUC, Jean-Nöel; ROBIN-ROMERO, Isabelle y ROLLET, Catherine (ed.). Lorsque l'enfant grandit. Entre dépendance et autonomie. Paris: Presses de I'Université de Paris-Sorbonne, 2003.

BARONA, Josep L. El Consejo Superior de Protección a la Infancia y Represión de la Mendicidad (1904-1914). Su ideología social y sanitaria. In PERDIGUERO, Enrique. Salvad al niño. Valencia: Seminari d’Estudis sobre la Ciència, 2004, pp. 121-155.

BECCHI, Egle. I bambini nella storia. Roma: Biblioteca Universale Laterza, 2010.

BECCHI, Egle y JULIA, Dominique. Storia dell'infanzia. Roma: Biblioteca Universale Laterza, 1996.

BEITER, Klaus Dieter. The Protection of the Right to Education by International Law. Lieden/Boston: Martinus Nijhoff Publishers, 2006.

BELOFF, Mary. Fortalezas y debilidades del litigio estratégico para el fortalecimiento de los estándares internacionales y regionales de protección a la niñez en América Latina, 2008, accesible en http://www.observatoriojovenes.com.ar/almacen/file/Fortalezas\%20y\%20debilidades_\%20 Mary\%20Beloff.pdf

BOLTANSKI, Luc. Puericultura e morale di classe. Firenze: Guaraldi, 1972.

CAMPOY, Ignacio. La fundamentación de los derechos de los niños. Modelos de reconocimiento y protección. Madrid: Dykinson, 2006.

CANTWELL, Nigel, The history, content and impact of the convention on the Rights of the Child. In VERHELLEN, Eugeen. Undestanding Children's Rights. Belgium: Children's Rigths Centre, University of Ghent, 1998, pp. 377-392.

CARDONA, Jorge. La Convención sobre los Derechos del Niño: significado, alcance y nuevos retos. Educatio Siglo XXI, v. 30, n. 2, pp. 47-68, 2012.

CASAS, Ferran. Infancia: perspectivas psicosociales. Barcelona: Paidós, 1998.

CASAS, Ferran. Representaciones sociales que influyen en las políticas sociales de infancia y adolescencia en Europa, Revista Interuniversitaria de Pedagogía Social, v. 17, pp. 15-28, 2010. 
CEPAL/UNICEF (2007). Maternidad adolescente en América Latina y el Caribe. Tendencias, problemas y desafíos. Santiago de Chile: Cepal/Unicef.

CEPAL/UNICEF (2009). Trabajo infantil en América Latina y el Caribe: su cara invisible. Santiago de Chile: Cepal/Unicef.

CEPAL/UNICEF (2013a). Los derechos de la infancia y de la adolescencia con discapacidad. Santiago de Chile: Cepal/Unicef.

CEPAL/UNICEF (2013b). Los derechos de las niñas y los niños indígenas. Santiago de Chile: Cepal/Unicef.

CEPAL/UNICEF (2014). América Latina a 25 años de la aprobación de la Convención sobre los Derechos del Niño. Santiago de Chile: Cepal/Unicef.

COMITÉ DE LOS DERECHOS DEL NIÑO. Observación General nº 1. Párrafo 1 del Artículo 29: Propósitos de la Educación. Ginebra, Comité de los Derechos del Niño, 2001.

CRC/GC/2001/1

COMITÉ DE LOS DERECHOS DEL NIÑO. Observación General $n^{\circ} 4$. La salud y el desarrollo de los adolescentes en el contexto de la Convención sobre los Derechos del Niño, 2003. $\mathrm{CRC} / \mathrm{GC} / 2003 / 4$

COMITÉ DE LOS DERECHOS DEL NIÑO. Observación General $n^{\circ} 7$. Realización de los derechos del niño en la primera infancia. Ginebra, Comité de los Derechos del Niño, 2005. $\mathrm{CRC} / \mathrm{C} / \mathrm{GC} / 7 / \mathrm{Rev} .1$

COMITÉ DE LOS DERECHOS DEL NIÑO. Observación General $n^{\circ}$ 9. Los derechos de los niños con discapacidad. Ginebra, Comité de los Derechos del Niño, 2006. CRC/C/GC/9

COMITÉ DE LOS DERECHOS DEL NIÑO. Observación General $n^{\circ} 12$. Derecho del niño a ser escuchado. Ginebra, Comité de los Derechos del Niño, 2009. CRC/C/GC/12

COMITÉ DE LOS DERECHOS DEL NIÑO. Observación General $n^{\circ} 17$. Derecho del niño al descanso, el esparcimiento, el juego, las actividades recreativas, la vida cultural y las artes (artículo 31). Ginebra, Comité de los Derechos del Niño, 2013. CRC/C/GC/17

CORDERO, Matías. Towards an Emancipatory Discourse of Children's Rights. The International Journal of Children's Rights, vol. 20 n. 3, pp. 365-421, 2012.

DÁVILA, Paulí. Book review: Para a compreensão histórica da infância; La infancia en los siglos XIX y XX. Discursos e imágenes, espacios y prácticas e Historia de la infancia en América Latina. Paedagogica Historica, Vol. 46, n. 4, pp. 543-549, 2010. 
DÁVILA, Paulí y NAYA, Luis M. (ed). La Infancia en la Historia: espacios y representaciones, 2 vol. Donostia: Erein, 2005.

DÁVILA, Paulí y NAYA, Luis M. La evolución de los derechos de la infancia: Una visión internacional. Encounters on Education, vol. 7, pp. 71-93, 2006.

DÁVILA, Paulí y NAYA, Luis M. El derecho a la educación en Europa, una lectura desde los derechos del niño. Bordón, vol. 61, n. 1, pp. 61-75, 2009.

DÁVILA, Paulí y NAYA, Luis M. Naya (ed), Derechos de la Infancia y Educación inclusiva en América Latina. Buenos Aires: Granica, 2011.

DÁVILA, Paulí y NAYA, Luis M. Las políticas supranacionales del Unicef y la educación. Bordón, Vol 67, n. 1, pp. 25-38, 2015.

DEPAEPE, Marc. Understanding the history of childhood from the perspective of educationalization. In VERHELLEN, Eugeen. Undestanding Children's Rights. Belgium: Children's Rigths Centre, University of Ghent, pp. 39-66, 1998.

DETRICK, Sharon. United Nations Convention on the Rights of the Child. A guide to the “Travaux Préparatoires". Dordrecht/Boston/London: Martinus Nijhoff Publishers, 1992.

ECLAC and UNICEF. Child abuse: a painful reality behind closed doors. Santiago de Chile, Eclac and Unicef, 2009.

FASS, Paula S. Encyclopedia of Children and Childhood in History and Society, 4 vol. Farmington Hill: MI, The Gale Group, 2004.

GARCÍA MÉNDEZ, Emilio. Child Rights in Latin America: From 'Irregular Situation' to Full Protection. Ensayo Innocenti, nº 8, Innocenti Research Centre, Firenze, 1998.

GARIBO, Ana Paz. Los derechos de los niños: una fundamentación. Madrid: Ministerio de Trabajo y Asuntos Sociales, 2004.

GODIN, Paul. Les droits de l'enfant. Pages d'hier, Pager d'aujourd'hui. Paris: A. Maloine, 1911.

GUY, Donna. The Pan American Child Congresses, 1916-1942: Pan Americanism, child reform, and welfare state in Latin America. Journal of Family History, Vol. 23, n. 3, pp. 272291,1988 . 
LLOBET, Valeria. La producción de la categoría “niño-sujeto-de-derecho" y el discurso psi en las políticas sociales en Argentina. In LLOBET, Valeria (ed.). Pensar la Infancia desde América Latina, Buenos Aires: CLACSO, pp. 209-234, 2014.

LOPES, Alberto; MENDES DE FARIA FILHO, Luciano y FERNANDES, Rogério (organizadores). Para a compreensão histórica da infância. Belo Horizonte: Auténtica, 2007.

MALON, Agustín. ¿El derecho a una educación sexual? Entre los discursos de salvación y la ausencia del conocimiento, Educatio Siglo XXI, Vol. 30, n. 2, pp. 207-229, 2012.

MOODY, Zoe. Transnational treaties on children's rights: Norm building and circulation in the twentieth century. Paedagogica Historica, Vol. 50, n. 1-2, pp. 151-164, 2014.

MOODY, Zoe. The United Nations Declaration of the Rights of the Child (1959): Genesis, transformation and dissemination of a treaty (re)constituting a transnational cause. Prospects, Vol 45, pp. 15-29, 2015.

NUNES, Eduardo Silveira Netto. Os primeiros congresos panamericanos del niño (1916, 1919, 1922, 1924) e a participaçao do Brasil, in XIX Encontro Regional de Historia: Poder, Violencia e Exclusao. Sao Paulo, 8 a 12 de septiembre. CD-ROM, 2008.

NUNES, Eduardo Silveira Netto. A infância como portadora do futuro: América Latina 19161948. Sâo Paulo: Universidade de Sâo Paulo, 2011.

OCHAITA, Esperanza y ESPINOSA, M. Angeles. Hacia una teoría de las necesidades infantiles y adolescentes. Madrid: McGraw-Hill, 2004.

PADILLA, Antonio; SOLER, Alcira; ARREDONDO, Martha Luz y MOCTEZUMA, Lucia M. La infancia en los siglos XIX y XX. Discursos e imágenes, espacios y prácticas. México: Universidad Autónoma del Estado de Morelos, 2008.

REDLAMYC. Estudio de balance regional sobre la implementación de la Convención sobre los Derechos del Niño en América Latina y el Caribe. Impacto y retos a 20 años de su aprobación. REDLAMYC y Save the Children-Suecia, 2009.

RODRÍGUEZ, Jesús. Una marco teórico para la discriminación. México: Consejo para prevenir la discriminación, 2006.

RODRíGUEZ, Pablo y MANARELI, María Emma (coordinadores). Historia de la infancia en América Latina. Bogotá: Universidad Externado de Colombia, 2007. 
ROLLET, Catherine. La santé et la protection de l'enfant vues à travers les congrès internationaux (1880-1920), Annales de Démographie Historique, n. 1, pp. 97-116, 2001.

SALINAS, Silvia (coord.). Vivencias y relatos sobre el embarazo en adolescentes Una aproximación a los factores culturales, sociales y emocionales a partir de un estudio en seis países de la región. Panamá: Unicef y Plan Internacional, 2014. Informe accesible en http://plan-international.org/where-we-work/americas/publicaciones/vivencias-y-relatossobre-el-embarazo-en-adolescentes-1.

SÁNCHEZ, José. Puerilizado y adulterado: representaciones institucionales de la infancia. Universitas, Revista de Ciencias sociales y humanas, vol. 13, pp. 95-130, 2010.

SOSENSKI, Susana y ALBARRÁN, Elena Jackson (comps). Nuevas miradas a la historia de la infancia en América Latina: entre prácticas y representaciones. México: UNAM, 2012.

SOSENSKI, Susana. El niño consumidor: una construcción publicitaria de mediados de siglo XX, en Ciudadanos inesperados. Procesos de formación de la ciudadanía ayer y hoy, México, El Colegio de México / CINVESTAV, Departamento de Investigaciones Educativas, 2012.

THERBORN, Goran. Los derechos de los niños desde la constitución del concepto moderno de menor: un estudio comparado de los países occidentales. In MORENO, Luis, Intercambio social y desarrollo del bienestar. Madrid: Consejo Superior de Investigaciones Científicas, 1993.

TOMASEVSKI, Katarina. Human Rights Obligations in Education. The 4-A Scheme. Nijmegen: Wolf Legal Publishers, 2006.

UNICEF. Estado Mundial de la Infancia, 1981-82. Ginebra: Unicef, 1982.

UNICEF. Estado Mundial de la Infancia, 1982-83. Ginebra: Unicef, 1983.

UNICEF. Estado Mundial de la Infancia, 1985. Ginebra: Unicef, 1985.

UNICEF. Estado Mundial de la Infancia, 1986. Ginebra: Unicef, 1986.

UNICEF. Estado Mundial de la Infancia, 1987. Ginebra: Unicef, 1987.

UNICEF. Estado Mundial de la Infancia, 1988. Ginebra: Unicef, 1988.

UNICEF. Estado Mundial de la Infancia, 1989. Ginebra: Unicef, 1989. 
UNICEF. Estado Mundial de la Infancia, 1993. Ginebra: Unicef, 1993.

UNICEF. Estado Mundial de la Infancia, 1994. Ginebra: Unicef, 1994.

UNICEF. Estado Mundial de la Infancia, 1998. Ginebra: Unicef, 1998.

UNICEF. Estado Mundial de la Infancia, 1999. Ginebra: Unicef, 1999.

UNICEF. Estado Mundial de la Infancia, 2001. Ginebra: Unicef, 2001.

UNICEF. Estado Mundial de la Infancia, 2003. Ginebra: Unicef, 2002.

UNICEF. Estado Mundial de la Infancia, 2008. Ginebra: Unicef, 2007.

UNICEF. Estado Mundial de la Infancia, 2009. Ginebra: Unicef, 2008.

UNICEF. Estado Mundial de la Infancia, 2013. Ginebra: Unicef, 2013.

VERHELLEN, Eugeen. The convention of the Rigths on the Child. In VERHELLEN, Eugeen. Understanding Children's Rights. Belgium: Children's Rights Centre, University of Ghent, 1998, pp. 21-38. 
Recebido em 28/02/2015 Aprovado em 29/03/2015

Universidade do Estado de Santa Catarina - UDESC Programa de Pós-Graduação em História - PPGH Revista Tempo e Argumento Volume 07 - Número 14 - Ano 2015 tempoeargumento@gmail.com 